
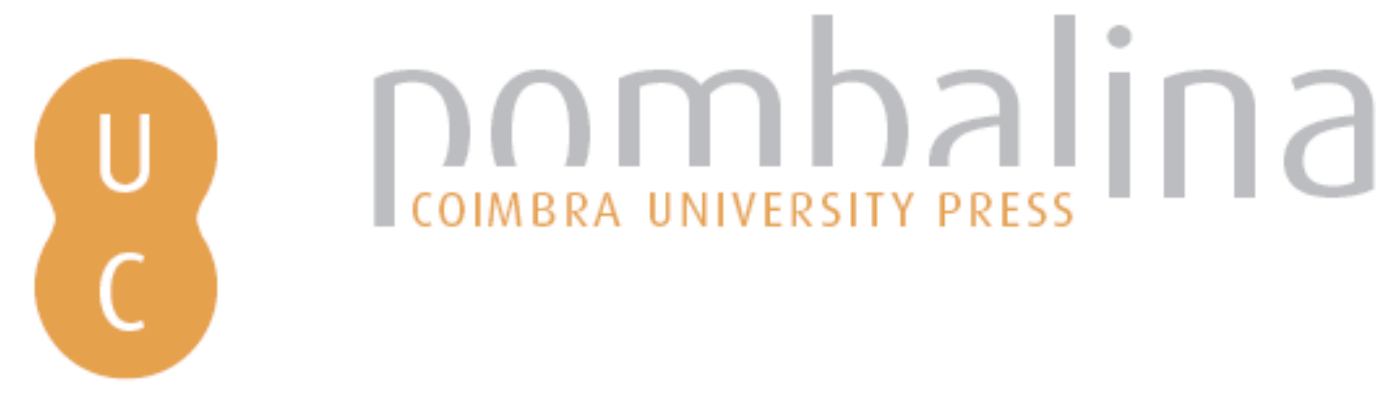

\title{
Pléctica: o estudo da simplicidade e da complexidade
}
Autor(es): Gell-Mann, Murray
Publicado por: Gradiva; Imprensa da Universidade de Coimbra
URL persistente:
URI:http://hdl.handle.net/10316.2/32653
DOI:
DOI:http://dx.doi.org/10.14195/978-989-26-0389-6_3

Accessed : $\quad$ 26-Apr-2023 12:12:08

A navegação consulta e descarregamento dos títulos inseridos nas Bibliotecas Digitais UC Digitalis, UC Pombalina e UC Impactum, pressupõem a aceitação plena e sem reservas dos Termos e Condições de Uso destas Bibliotecas Digitais, disponíveis em https://digitalis.uc.pt/pt-pt/termos.

Conforme exposto nos referidos Termos e Condições de Uso, o descarregamento de títulos de acesso restrito requer uma licença válida de autorização devendo o utilizador aceder ao(s) documento(s) a partir de um endereço de IP da instituição detentora da supramencionada licença.

Ao utilizador é apenas permitido o descarregamento para uso pessoal, pelo que o emprego do(s) título(s) descarregado(s) para outro fim, designadamente comercial, carece de autorização do respetivo autor ou editor da obra.

Na medida em que todas as obras da UC Digitalis se encontram protegidas pelo Código do Direito de Autor e Direitos Conexos e demais legislação aplicável, toda a cópia, parcial ou total, deste documento, nos casos em que é legalmente admitida, deverá conter ou fazer-se acompanhar por este aviso.

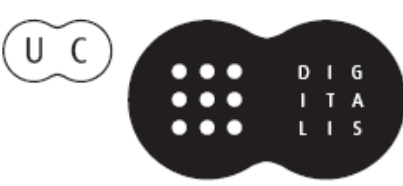


C I E N C I A I B E R T A

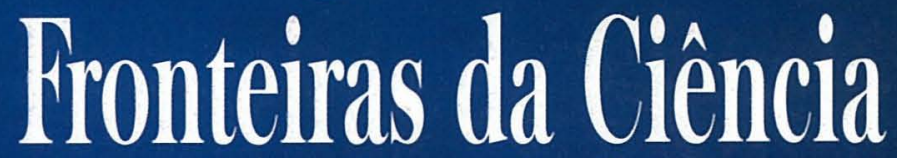

Desenvolvimentos Recentes - Desafios Futuros

RUI FAUSTO • CARLOS FIOLHAIS • JOÃO FILPE QUURRÓ

Coordenadores

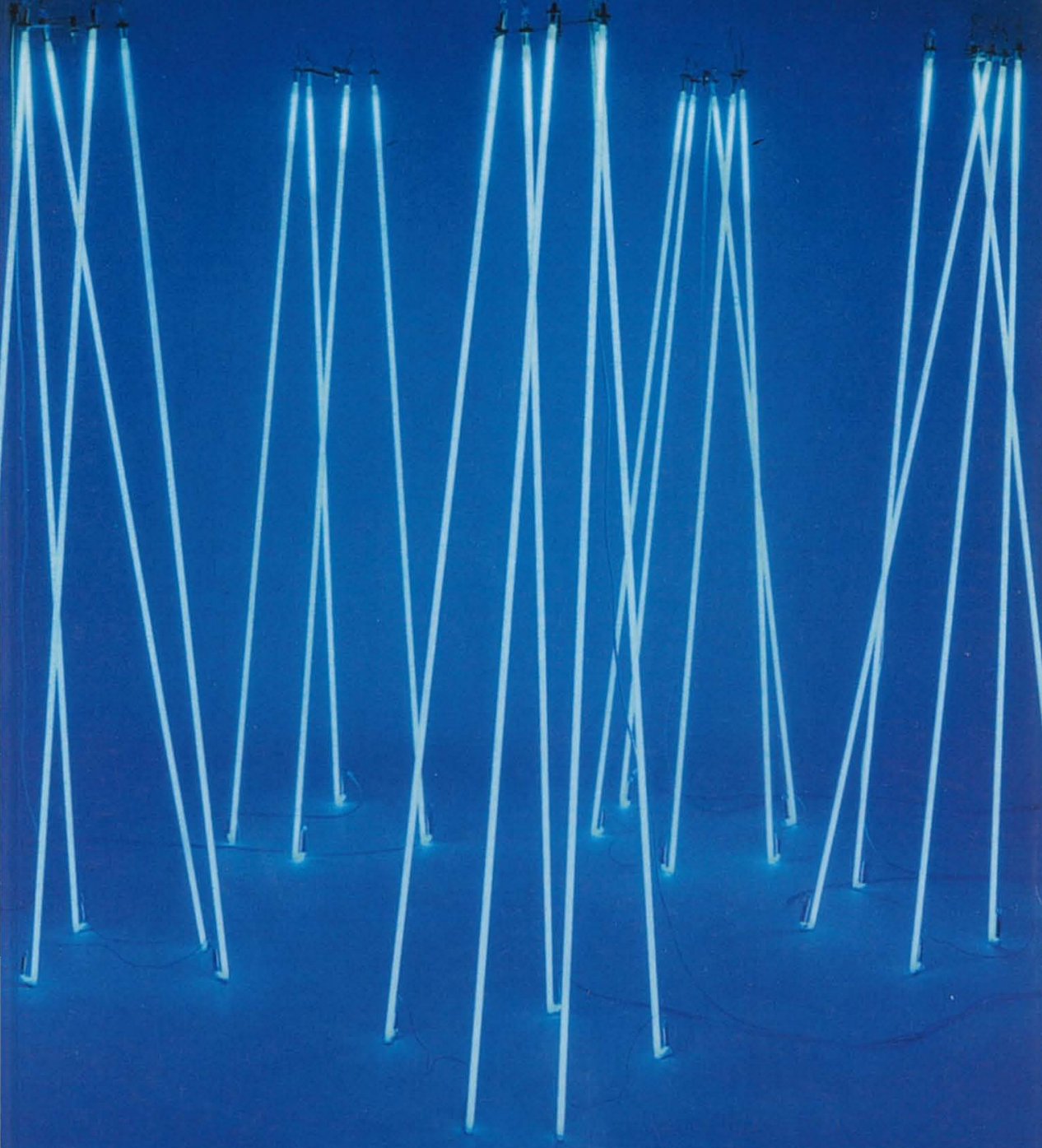

gradiva - Imprensa da Universidade de Coimbra 
(Página deixada propositadamente em branco) 


\section{RUI FAUSTO, CARLOS FIOLHAIS JOÃO FILIPE QUEIRÓ \\ Coordenadores}
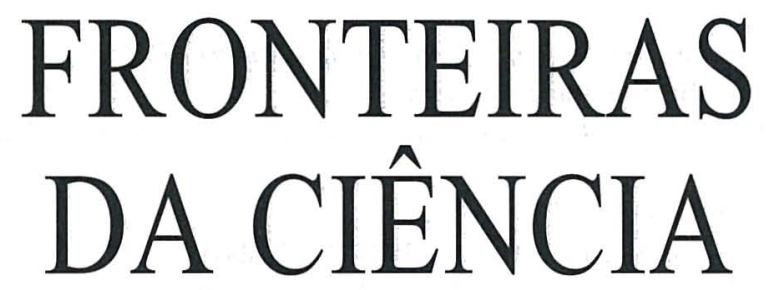

Desenvolvimentos Recentes Desafios Futuros 
(C) Gradiva - Publicações, L. da / Imprensa da Universidade de Coimbra, 2003 Coordenação editorial: Rui Fausto, Carlos Fiolhais e João Filipe Queiró Tradução: Jean Burrows, Vivien Burrows, Rui Fausto, Carlos Fiolhais e João Filipe Queiró

Revisão do texto: Isabel Pedrome

Capa: António Barros [Imprensa da Universidade. Coimbra], sobre imagem de «Águas Vivas», escultura de Silvestre Pestana, 2001

Foto: António Alves; Infografia: ESTÍMULUS [design]; Cortesia: Galeria Alvarez-Arte Contemporânea

Paginação: António Resende e Paula Isabel Jorge

Impressão e acabamento: G.C. - Gráfica de Coimbra, L. ${ }^{d a}$

Reservados os direitos para Portugal por:

Gradiva - Publicações, L. ${ }^{\text {da }}$ e Imprensa da Universidade de Coimbra

Gradiva - Publicações, L.da

Rua Almeida e Sousa, 21, r/c, esq.•1399-041 Lisboa

Telefs. $213974067 / 8 \cdot 213971357 \cdot 213953470$

Fax $213953471 \cdot$ Email: gradiva@ip.pt

URL: http://www.gradiva.pt

Imprensa da Universidade de Coimbra

Rua Antero de Quental, 195 • 3000-033 Coimbra

Telefs. 351239853110

Fax 3512398531 19・e-mail: fjrpress@ci.uc.pt

URL: http://www.imp.uc.pt

ISBN: 972-662-923-3

1." edição: Agosto de 2003

Depósito legal n. ${ }^{\circ} 199$ 463/2003 
Murray Gell-Mann

Santa Fe Institute

Santa Fe

E. U.A.

\section{Pléctica: o estudo da simplicidade e da complexidade}

É um prazer comunicar com Coimbra através do sistema de teleconferência. Lamento muito não poder estar presente pessoalmente, pois há muito tempo que queria visitar essa antiga e maravilhosa universidade.

Vamos hoje debruçar-nos sobre o tema a que chamo pléctica, o estudo da simplicidade e da complexidade. No Santa Fe Institute, que ajudei a criar, lidamos principalmente com assuntos que se relacionam com a simplicidade e a complexidade. Cheguei ao nome pléctica da seguinte forma: a palavra complexo vem de plexus, que significava originalmente entrelaçado, e com-, que significa uns com os outros, ou seja complexo significa entrelaçados uns com os outros. Do mesmo modo, simples deriva de raízes que significam dobrados uma única vez. As palavras latinas que significam entrelaçado e dobrado têm a sua origem mais remota na raiz indo-europeia plek-. Em grego, esta raiz origina plektos, que significa entrelaçado. Assim, usando a palavra plética estou a descrever o assunto da simplicidade e da complexidade sem dizer se estou a falar sobre algo simples ou complexo.

O que entendemos então por complexidade e pelo seu oposto, simplicidade? Seriam precisos muitos conceitos, muitas quantidades, para captar todos os diferentes significados implícitos no nosso uso da palavra complexidade. Mas existe um conceito - a que chamo 
complexidade efectiva - que representa de forma bastante aproximada aquilo que normalmente queremos dizer quando usamos esta palavra em linguagem vulgar ou no discurso científico. Uma definição não técnica de complexidade efectiva seria o comprimento de uma descrição extremamente comprimida das regularidades de uma determinada entidade. A compactação - a eliminação da redundância — é muito importante; de outra forma o comprimento da mensagem preocupar-nos-ia muito pouco.

No meu livro $O$ Quark e o Jaguar ${ }^{1}$ refiro o caso da professora da escola primária que pediu aos alunos que escrevessem uma redacção de 300 palavras como trabalho de casa para o fim de semana. Um aluno que passou o fim de semana a brincar na rua (como eu fiz em criança) gatafunhou à pressa, já na segunda-feira de manhã, o seguinte: Ontem, os vizinhos tiveram um incêncio na cozinha. Eu pus a cabeça de fora da janela e comecei a gritar fogo!, fogo!, fogo! fogo!, fogo! fogo!, ... Escreveu a palavra fogo um número de vezes suficiente para cumprir a exigência das 300 palavras da redacção. Contudo, poderia ter comprimido aquela descrição dizendo Pus a cabeça de fora da janela e comecei a gritar fogo! 280 vezes. Mas a professora insistia num ensaio com 300 palavras!

Um modo de considerar a compactação consiste na utilização do conceito de conteúdo algorítmico de informação, com o qual muitos estão certamente familiarizados. Ele foi definido para uma cadeia de $b_{i t s^{2}}$, que é uma cadeia de zeros e uns ou uma entidade que é descrita por uma cadeia de zeros e uns. O conteúdo algorítmico de informação é o comprimento de programa mais curto que pode fazer que um dado computador universal $U$ imprima aquela cadeia de bits e, de seguida, termine imediatamente o cálculo.

Qualquer tipo de definição que utilize o comprimento da descrição, mesmo o comprimento de uma descrição muito concisa, envolve uma certa arbitrariedade ou dependência contextual. Estamos a descrever uma dada entidade e a descrição está codificada sob a forma de uma cadeia de bits. Obviamente que é relevante o grau de detalhe com que descrevemos o objecto. Em física chama-se a isto granularidade grossa.

1 O Quark e o Jaguar: Aventuras no Simples e no Complexo, Gradiva, 1997. (N. do T.)

2 Bit significa binary digit, em português, algarismo binário. (N. do T.) 
A linguagem na qual está expressa a descrição original pode também interessar, e o conhecimento e a compreensão do mundo partilhados com o correspondente são certamente importantes. Todas estas coisas ajudam a determinar o comprimento da descrição. Quando a descrição é codificada sob a forma de uma cadeia de bits para ser impressa por um computador passamos a ter uma dependência contextual adicional, devida à convenção utilizada no código escolhido e também à escolha do computador universal. Mas, se considerarmos toda esta dependência de contexto, podemos oferecer uma definição mais técnica da complexidade efectiva: o conteúdo algorítmico de informação das regularidades de um objecto. Isto significa que a totalidade do conteúdo algorítmico de informação do objecto é dividida em dois termos - um que descreve as suas regularidades e outro que descreve as restantes características, que são consideradas acidentais ou aleatórias.

Deixem-me usar estas gravatas como exemplo. Aqui no Novo México usamos estas gravatas tradicionais fabricadas pelos índios locais, mas noutros sítios, em ocasiões um pouco mais formais, como esta, usaríamos uma gravata normal. Há alguns anos, estas gravatas com riscas diagonais paralelas vermelhas e amarelas estavam muito na moda. Podemos ver que esta gravata é muito simples. O comprimento da sua descrição é trivial - podemos incluir apenas as cores, largura e espaçamento das riscas e a cor de fundo da gravata. Contudo, deve notar-se que estamos aqui a fazer a distinção entre as regularidades no padrão e várias outras características da gravata que consideramos aleatórias ou acidentais, tais como as nódoas de sopa ou as pequenas irregularidades do tecido... Estas características não estão incluídas na descrição.

Se nos concentrarmos apenas nas regularidades apresentadas pelo padrão desta outra gravata, concluímos que, contrariamente à anterior, ela é bastante complexa. É uma gravata de Austin, no Texas, pintada à mão, e levaria muito tempo descrever a regularidade do seu padrão. A sua complexidade efectiva é elevada. Estas gravatas estiveram na moda há dois ou três anos, mas agora estão fora de moda e regressámos às gravatas simples, muitas vezes com riscas horizontais em vez de diagonais.

Consideremos agora uma cadeia de bits constituída unicamente por uns. Ela é, obviamente, muito simples, visto que é muito fácil descrever a sua regularidade. Tem uma complexidade efectiva muito pequena, bem como um baixo conteúdo algorítmico de informação.

No outro extremo da escala de conteúdo algorítmico de informação teríamos uma longa cadeia de bits quase sem regularidades - uma cadeia de zeros e uns incompressível ou aleatória, sem regularidades, excepto o comprimento. O seu conteúdo algorítmico de informação é muito 
elevado. Na verdade, ele toma o valor máximo possível para aquele comprimento de cadeia. O programa mais curto para a descrever seria um que dissesse «Escrever», seguido pela própria cadeia de bits. Apesar de ter o maior conteúdo algorítmico de informação possível, a sua complexidade efectiva é novamente muito pequena porque não possui quaisquer regularidades, excepto o comprimento.

Então, em ambos os casos extremos, para uma cadeia muito simples e para uma muito desordenada, existe uma complexidade efectiva pequena. A complexidade efectiva pode ser grande apenas entre estes extremos, para qualquer coisa que caia entre as situações extremas de ordem e desordem: qualquer coisa que tenha muitas regularidades diferentes.

Não existe um procedimento matemático bem definido que permita garantidamente encontrar todas as regularidades de uma cadeia de bits ou de uma entidade descrita por ela. Em geral, identificamos regularidades através de informação partilhada, conhecida tecnicamente por informação mútua. Se processarmos uma cadeia de bits de certa maneira e verificarmos que depois a podemos dividir em duas ou mais partes e que estas partilham um conjunto de informação, então podemos concluir que existe uma regularidade nessa cadeia. Apesar de a informação mútua ser um diagnóstico da regularidade, ela não nos fornece uma medida do conteúdo algorítmico de informação dessa regularidade; por isso, a informação mútua é bastante distinta da complexidade efectiva.

Embora haja mecanismos que permitem identificar regularidades, não existe, tal como já indiquei, nenhum procedimento matemático que possa garantir a identificação de todas as regularidades. Sendo assim, a complexidade efectiva, o conteúdo algorítmico de informação das regularidades, depende em parte de quem ou do que descreve o objecto.

Voltemos às nossas gravatas. Recordemos que, quando analisámos a complexidade efectiva dos padrões, ignorámos os diferentes tipos de manchas. Contudo, suponhamos que éramos empregados de uma lavandaria a seco. Nesse caso não daríamos grande importância aos padrões das gravatas; em vez disso, concentrar-nos-íamos nas nódoas de sopa, de sangue, de vinho, etc. Estas são as regularidades importantes para o empregado da lavandaria.

$\mathrm{O}$ que são os sistemas que identificam regularidades perceptíveis e comprimem a sua descrição numa mensagem breve? Estes sistemas são aquilo que designamos por sistemas adaptáveis complexos, os sistemas que aprendem, ou se adaptam, ou evoluem do mesmo modo que os seres vivos. Cada um de nós é um sistema destes, capaz de identificar regularidades perceptíveis na cadeia de dados que nos atingem e de distingui-las daquilo que percepcionamos como aleatório ou acidental, 
comprimindo de seguida a descrição dessas regularidades numa mensagem breve.

Podemos descrever o modo como um sistema adaptável complexo funciona. Começa por receber uma cadeia de dados sobre o universo, incluindo ele próprio. Certas regularidades presentes nos dados são identificadas e comprimidas numa mensagem muito curta, a que chamo esquema. Este esquema pode ser usado, conjuntamente com alguns dados adicionais presentes na cadeia de dados original, para descrever características do universo, prever o comportamento de objectos no universo, ou determinar comportamentos a assumir pelo sistema adaptável complexo: a descrição pode ser melhor ou pior; as previsões podem revelar-se verdadeiras ou falsas; a prescrição de um determinado comportamento no mundo real pode resultar em sucesso ou em fracasso, sobrevivência ou desaparecimento. Estas consequências desenvolvidas no mundo real são então devolvidas ao sistema adaptável complexo, de forma a condicionar os processos internos de selecção entre os vários esquemas em competição (apesar de um esquema ter de possuir algum grau de estabilidade ou robustez, tem também de ser capaz de experimentar pequenas variações, sofrer mutações mais drásticas ou mesmo de ser substituível por outro).

Todos os exemplos de sistemas adaptáveis complexos existentes na Terra, pelo menos todos aqueles que conhecemos, estão relacionados de alguma forma com a vida, embora não sejam necessariamente formas de vida ou mesmo partes ou associações de sistemas vivos. Além disso, têm tendência para originar outros sistemas adaptáveis complexos.

Entre os sistemas adaptáveis complexos do nosso planeta encontravam-se as reacções químicas pré-bióticas que originaram as formas primordiais de vida. Assim, a evolução biológica é um sistema adaptável complexo, tal como o comportamento de cada organismo individual resultante da evolução biológica. Partes dos organismos podem também funcionar como sistemas adaptáveis complexos - por exemplo, o nosso sistema imunológico. O funcionamento do cérebro humano, conduzindo à aprendizagem e ao pensamento individual, é também um sistema adaptável complexo. Podemos também observar o comportamento de grupos organizados de pessoas: a evolução cultural humana em geral é um sistema adaptável complexo e as organizações humanas, tais como as empresas, evoluem como sistemas adaptáveis complexos.

Há também sistemas adaptáveis complexos não vivos. Os nossos computadores são agora suficientemente sofisticados para possibilitar que neles se estabeleçam sistemas adaptáveis complexos, em geral através da utilização de software. Onde está, neste caso, a ligação com a vida? Bem, 
existe uma concordância generalizada em relação a os maníacos dos computadores que aperfeiçoaram o software para estes sistemas adaptáveis complexos serem de facto seres vivos!

O que são então os esquemas? Consideremos um sistema adaptável complexo muito familiar que envolve muitos seres humanos, nomeadamente o empreendimento científico, no qual a maior parte de nós participa. Os esquemas são aqui as teorias. As teorias são robustas e, em geral, quando alcançam sucesso na previsão das propriedades do mundo real, sobrevivem. Quando as observações cuidadosamente realizadas conduzem sistematicamente a resultados que não concordam com a teoria, esta é modificada ou substituída por outra.

Além do empreendimento científico, no qual os esquemas são as teorias, podemos considerar a evolução biológica, onde os esquemas são os genótipos, e a evolução da sociedade humana, onde os esquemas são as leis, as tradições, os mitos, os costumes e por aí fora. Estes esquemas são constituídos por unidades que Richard Dawkins baptizou de memes, que desempenham um papel análogo ao dos genes na evolução biológica. O ADN cultural para a evolução social é constituído por conjuntos de memes.

Voltemos de novo aos sistemas adaptáveis complexos nos computadores. Existem algoritmos genéticos que se baseiam numa analogia muito imperfeita com a evolução biológica. Existem as designadas redes neuronais, que se baseiam numa analogia muito imperfeita com a forma como se pensa que o sistema nervoso humano - em especial o cérebro - funciona. Mas poderia haver muitos mais. Poderíamos ter dezenas de tipos diferentes de métodos computacionais adaptáveis e tais métodos não teriam de se basear em analogias com modelos do cérebro ou da evolução biológica. Tem de existir uma classe muito vasta de sistemas adaptáveis complexos nos computadores. O que é esta classe? Que membros dessa classe podem ser utilizados para resolver cada tipo de problema? Sabemos que há problemas para os quais os algoritmos genéticos são adequados, enquanto noutros casos estes algoritmos não têm utilidade nenhuma. O mesmo se pode dizer das redes neuronais - há certos problemas de optimização, por exemplo, para os quais as redes neuronais funcionam muito bem, enquanto existem outros para os quais não funcionam. Pode demonstrar-se que não existe nenhum sistema adaptável complexo num computador que seja bom para todos os problemas de optimização. Cada um tem o seu domínio de aplicação, e é um grande desafio para a teoria compreender todas as classes de sistemas adaptáveis complexos nos computadores e descobrir qual é o melhor para cada espécie de problema. 
Devo agora chamar a atenção para o facto de nem toda a gente usar a minha notação. John Holland, o inventor original dos algoritmos genéticos e meu colega e amigo, usa uma terminologia diferente. Aquilo a que eu chamo sistema adaptável complexo é algo semelhante ao que ele designa por modelo interno. Ele usa a expressão sistema adaptável complexo para designar o que eu chamaria agregação fraca de sistemas adaptáveis complexos que se assemelham um aos outros (os exemplos destes sistemas incluem um mercado constituído por investidores e um sistema ecológico constituído por organismos). Ao usarmos diferentes terminologias estamos ambos a ilustrar o famoso adágio que afirma que um cientista mais facilmente usaria a escova de dentes de outra pessoa do que a nomenclatura inventada por outro cientista.

Por vezes uma aparente complexidade não reflecte uma complexidade efectiva elevada. Além do comprimento do programa mais curto que faria um determinado computador universal imprimir a descrição das regularidades da entidade em questão, temos também de considerar quanto tempo levaria o computador a imprimir a descrição com esse programa simples. Esta propriedade é conhecida por profundidade lógica das regularidades, conforme foi salientado por Charles Bennett.

Consideremos, por exemplo, os níveis de energia de um núcleo atómico. As regras que determinam esses níveis de energia parecem à primeira vista muito complicadas, mas acreditamos actualmente que elas se podem obter a partir de um par de teorias físicas simples: a electrodinâmica quântica (a teoria quântica de campos das interacções electromagnéticas) e a cromodinâmica quântica (a teoria quântica de campos dos quarks e gluões). Acreditamos que, se unificássemos estas duas teorias, obteríamos uma descrição muito detalhada dos núcleos atómicos, incluindo os valores de todos os seus níveis de energia. Mas os cálculos computacionais são extremamente longos e difíceis nos computadores actualmente existentes, usando métodos conhecidos de cálculo, e a maior parte deles não foram ainda efectuados. Este é, pois, um caso em que estamos aparentemente a lidar com algo muito complexo, mas que tem, de facto, uma complexidade efectiva reduzida, embora possua bastante profundidade lógica. Por outras palavras, o problema envolve um programa curto, mas associado a um tempo de computação muito longo.

Consideremos agora um caso em que não estamos ainda certos se a complexidade aparente reflecte a existência de uma complexidade efectiva elevada ou de uma grande profundidade lógica. Constituem as características universais da bioquímica na Terra um sistema único? Ou há muitos tipos diferentes de bioquímicas possíveis para sistemas que se 
assemelham à vida, florescentes noutros planetas que gravitam em torno de outras estrelas, noutras partes do universo? Não parece existir nada particularmente especial no nosso sistema solar ou no nosso planeta ou, por isso, na vida, que apareceu cedo na Terra, logo após o intenso bombardeamento a que esta esteve sujeita. É mais provável, então, que haja muitos mais planetas no universo que possuam qualquer coisa semelhante à vida, isto é, sistemas adaptáveis complexos com uma química que se assemelha de alguma maneira à bioquímica terrestre. Mas terão essas bioquímicas de ser iguais? Ou há uma vasta gama de bioquímicas possíveis? Não sabemos realmente, e os especialistas não estão de acordo nesta matéria.

Alguns deles pensam que os constrangimentos fundamentais da física limitam as bioquímicas a apenas um reduzido número de possibilidades. Outros teóricos acreditam que há muitas bioquímicas possíveis, das quais temos um exemplo aqui na Terra. Se aceitarmos as ideias do primeiro conjunto de teóricos, a bioquímica tem uma complexidade efectiva reduzida porque pode ser obtida a partir das leis da física. A forma de a obter pode, contudo, ser longa, o que implicaria uma boa dose de profundidade lógica. Por outro lado, se os outros teóricos estiverem correctos, a bioquímica na Terra tem uma complexidade efectiva apreciável, visto que dependerá tanto dos acidentes inesperados e casuais da história como da física fundamental.

Este problema conduz à questão do modo como surge a complexidade no universo. De onde surge a complexidade efectiva? Aqueles que estudam as leis fundamentais da física acreditam, tal como eu, que essas leis são extremamente simples. Existem apenas duas dessas leis. A primeira é uma teoria unificada de todas as partículas elementares e de todas as forças da natureza. Pode ser que esta teoria tenha já sido formulada, na forma da maravilhosa candidata que brotou da teoria das super cordas e hoje é conhecida por Teoria $M$. O outro princípio fundamental da física é a condição inicial do universo, nas proximidades do início da sua expansão, há cerca de 10 mil milhões de anos. Esta pode também ser simples. De facto, têm sido propostas algumas ideias específicas segundo as quais a condição inicial do universo poderia ser simples.

Há cem anos teríamos dito que, dadas a teoria fundamental e a condição inicial, poderíamos em princípio prever toda a história do universo. Mas hoje sabemos que não é assim. As nossas teorias são probabilísticas em vez de totalmente determinísticas. Por isso, a história do universo é determinada simultaneamente por estes dois princípios fundamentais e pela sequência inconcebivelmente longa de acidentes 
inesperados e casuais, com vários resultados diferentes possíveis. Antes de cada acontecimento, só estão disponíveis as probabilidades relativas associadas aos vários resultados possíveis. Um exemplo muito simples retirado da experiência laboratorial é a desintegração radioactiva de um núcleo atómico, com emissão, por exemplo, de uma partícula alfa. A direcção segundo a qual essa partícula é ejectada é absolutamente indeterminável antes de ela ser observada; todas as direcções são igualmente prováveis. No entanto, quando ela é de facto observada torna-se fácil descobrir a direcção segundo a qual foi emitida.

Podemos pensar nas histórias alternativas do universo como formando uma árvore ramificada com uma determinada probabilidade associada a cada um dos ramos. À medida que o tempo passa e uma dada ramificação é atingida, um dos seus ramos é seleccionado. Contudo, antes de a ramificação surgir existem apenas probabilidades para as diferentes alternativas.

O notável escritor argentino Jorge Luís Borges escreveu um pequeno conto intitulado $O$ Jardim das Encruzilhadas, no qual alguém construiu, sob a forma desse jardim, um modelo de histórias ramificadas do universo.

Pensemos apenas nos vários acidentes inesperados e casuais que tiveram como resultado nós próprios: a pequena flutuação que produziu a nossa galáxia; os acontecimentos que foram responsáveis pela formação do nosso sistema solar; os acidentes que determinaram as características da Terra; os acidentes que deram origem à vida, durante a alvorada da história da Terra; todos os acidentes associados à evolução biológica que, conjuntamente com a selecção natural, conduziram ao aparecimento das formas de vida actuais, incluindo os seres humanos; e depois, os acidentes do espermatozóide e do ovo, da selecção sexual, do desenvolvimento no interior do útero e na infância que conduziram a cada um dos adultos que nós somos.

Entre os acidentes inesperados e casuais da história do universo alguns são mais geradores de informação mútua, mais geradores de regularidades que outros. A flutuação que deu origem à nossa galáxia, por exemplo, pode não ser considerada muito importante à escala cósmica, mas para tudo o que nela existe é de enorme importância que a galáxia tenha tido oportunidade de surgir. Da mesma forma, muitos eventos na história da humanidade representam ramificações com consequências de enorme relevância para a história futura da humanidade na Terra.

Hoje em dia, os historiadores gostam de se referir a Annie Oakley, a famosa mulher pistoleira que fazia parte do elenco do espectáculo Buffalo Bill Cody's Wild West Show, que fez uma digressão pela Europa em 1889. Num dos números do espectáculo, Annie Oakley oferecia-se para, com 
um tiro, fazer saltar parte de um charuto da boca de um espectador que se oferecesse como voluntário. Normalmente, ninguém se oferecia para esta experiência arriscada e o seu marido, também ele um famoso atirador, saltava para a frente com o seu charuto. Annie Oakley acertava nas cinzas do charuto do seu marido e a assistência aplaudia. Mas em Berlim, em 1889 , surgiu um voluntário da audiência - o Kaiser. Ele estava no trono há pouco mais de um ano quando se ofereceu para ser a vítima do número de destreza de Annie Oakley. Ela estava preocupada com a sua pontaria — tinha bebido muito na noite anterior - mas não teve escolha. O Kaiser retirou a cinta do seu caro charuto Havana, aparou-1he a ponta com um cortador de prata, pô-lo na boca e acendeu-o. Annie apontou à extremidade do charuto e acertou nas cinzas. Não matou o Kaiser, mas o que aconteceria se o tivesse feito? A história teria sido provavelmente bastante diferente. A Primeira Guerra Mundial teria sido muito diferente - de facto, poderia nunca ter acontecido - e por aí fora. Aqui temos um exemplo de um acidente congelado, um acontecimento casual que produz uma grande quantidade de informação mútua futura numa porção do universo que nos interessa.

Podemos agora responder à pergunta: por que razão há, em tantos domínios da experiência, uma tendência para que, à medida que o tempo passa, surjam entidades cada vez mais complexas? As leis fundamentais da natureza, como vimos, são muito simples, incluindo a condição inicial do universo. Mas essas leis são probabilísticas. A evolução histórica dá-se numa árvore ramificada de probabilidades, com acidentes junto às ramificações. Alguns desses acidentes - os acidentes congelados - são mais importantes que outros. À medida que o tempo flui, mais e mais acidentes congelados podem ser acumulados, tornando possível a emergência de mais e mais regularidades. Se a acumulação de resultados de acidentes congelados se sobrepõe à sua eliminação, surgem coisas cada vez mais complexas com o passar do tempo. Não é, naturalmente, verdadeiro que cada coisa individual se torne mais complexa. Longe disso! Por exemplo, organismos e civilizações morrem e ficam, obviamente, muito menos complexos ao longo desse processo. Mas o que podemos afirmar é que em muitos casos o conteúdo de complexidade tende a crescer à medida que o tempo passa, de tal forma que são produzidas entidades cada vez mais complexas.

$\mathrm{O}$ aparecimento de entidades progressivamente mais complexas com o passar do tempo não é de forma nenhuma incompatível com a famosa segunda lei da termodinâmica, que afirma que a desordem média, a entropia média, de um sistema fechado tem tendência para aumentar com o tempo. Mas isso é assim no caso da desordem média - não há nada 
que impeça a existência de mecanismos de auto-organização capazes de produzir ordem local a expensas de uma maior desordem noutro lugar. Conhecemos muitos mecanismos de auto-organização, por exemplo a atracção gravitacional, que produziu as galáxias, estrelas, planetas, rochas, etc. Do mesmo modo, as temperaturas baixas originam formas belas e regulares como os cristais ou os flocos de neve.

Deixem-me concluir com uma interrogação sobre o futuro. Continuarão a aparecer no universo coisas cada vez mais complexas? Ora nós não temos a certeza, mas podemos especular acerca disso. Muitos físicos teóricos acreditam, apesar de até agora as experiências não o terem ainda provado, que acabará por se descobrir que o protão é instável. Se for assim, os núcleos atómicos são instáveis, com tempos de vida talvez da ordem de grandeza de $10^{35}$ anos (isto é, um um seguido de 35 zeros um número muito grande de anos). Passado algum desse tempo, grande parte dos núcleos teria desaparecido e os átomos e as moléculas teriam desaparecido também. A maioria das regularidades com que estamos familiarizados teria desaparecido e poderia então acontecer que entidades mais complexas não continuassem a surgir. De facto, o conteúdo de complexidade poderia começar a encolher quando a maior parte dos núcleos tivesse desaparecido. Contudo, este não é assunto que nos deva preocupar de imediato. Temos hoje em dia, certamente, preocupações muito mais urgentes! 
 \\ A palavra "fronteiras" pode ser tomada em} diferentes sentidos. Pode referir-se aos limites, necessariamente provisórios, entre o conhecido e o desconhecido, ou aos limites entre o possivel e o impossivel, e, dentro do possivel, entre o desejável e 0 indesejável. Fronteiras podem também ser as delimitações, nem sempre nítidas, entre ciência e não-ciência, e dentro da ciência, entre as várias disciplinas. Quais são então as fronteiras da ciência?

Neste livro, a resposta a esta pergunta é dada, segundo as mais diferentes perspectivas, por um conjunto notável de personalidades, cientistas ou não, entre as quais se contam três Prémios Nobel.

Rui Fausto, Carlos fiolhais e JoÃo Fillipe Queiró são, respectivamente, professores de Química, Física e Matemática na Faculdade de Ciências e Tecnologia da Universidade de Coimbra. 